\title{
NbC Precipitation and Deformation of SS 347H Crept at $850^{\circ} \mathrm{C}$
}

\author{
Babak Shalchi Amirkhiz, Su Xu \\ CanmetMATERIALS, Natural Resources Canada, Hamilton, Canada
}

Niobium stabilized $347 \mathrm{H}$ stainless steel is a candidate alloy for fuel cladding of Generation IV Supercritical Water-Cooled Reactors (SCWR). The creep properties and microstructural evolution of SS $347 \mathrm{H}$ are vitally important for the proposed SCWR challenging design conditions. The high temperature mechanical properties and phase stability of stainless steels is linked to formation, dissolution and coarsening of precipitates [1]. In solution annealed and aged condition, type 347 stainless steel forms $\mathrm{NbC}$ precipitates which stabilise the steel against grain boundary precipitation of $\mathrm{M}_{23} \mathrm{C}_{6}$ to reduce sensitization [2]. However, to the authors' knowledge, microstructural investigation on crept specimens at $850^{\circ} \mathrm{C}$ is not available. In this study precipitation and deformation behaviours of a commercial SS $347 \mathrm{H}$ plate $(17 \% \mathrm{Cr}, 9 \% \mathrm{Ni}, 0.36 \% \mathrm{Nb}, 0.04 \% \mathrm{C})$ in the as received, aged at $850^{\circ} \mathrm{C}$ for $1244 \mathrm{~h}$ (i.e., TEM sample taken from the head of creep specimen) and the creep conditions were examined using the FEI Tecnai Osiris ${ }^{\mathrm{TM}}$ TEM equipped with Super X field emission gun and ChemiSTEM ${ }^{\mathrm{TM}}$ X-ray detection technology operating at $200 \mathrm{kV}$.

In Fig 1(A) typical $\mathrm{NbC}$ precipitates within the matrix in the as received condition are shown. Figure 1(B) is an HRTEM image of one of these precipitates that appears to be coherent with the matrix. An overlay of $\mathrm{Nb}$ EDX map on a high angle annular dark field (HAADF) image of this sample is shown in Fig 1(C), highlighting uniformly distributed precipitates. In the aged condition, Fig 2 presents a series of micrographs showing distribution of the $\mathrm{NbC}$ precipitates within the matrix and also at grain boundaries. In the crept sample, Fig. 3(A) is a STEM-HAADF image with CBED inset representing [011] zone axis and Fig. 3(B) shows the corresponding EDX elemental map highlighting the NbC precipitates of the crept specimen. These precipitates were found to be aligned towards $<111>$ slip direction (Fig. 3(B)). The slip lines visible in Fig 3(A) were analysed in HRTEM image of Fig 3(C), where the inset is the corresponding fast Fourier transform (FFT). From the FFT pattern the ( $\overline{1} \overline{1} 1)$ spot was used to form the masked inversed FFT shown in Fig 3(D), illustrating the effect of slip in ( $\overline{1} \overline{1} 1)$ planes. Figure $3(\mathrm{E})$ is a dark field TEM image formed using (1 $\overline{1} \overline{1}$ ) reflection of a cubic NbC precipitate circled in Fig 3(B). Figures $3(\mathrm{~F})$ and $(\mathrm{G})$ compare the deformation in the matrix of the aged and the crept samples. In the high resolution STEM images, Moiré fringes magnify the effect of defects within the matrix, and are indicative of the deformation. Arrows point to the image of the dislocations in Moiré fringes and illustrate severe deformation in the crept sample as opposed to the aged sample. Figure 3(G) also implies that the $\mathrm{NbC}$ precipitate (circled in 3(B)) is oriented towards slip lines of creep deformation. In all samples larger $\mathrm{NbC}$ precipitates were also found in grain boundaries. It is interesting to note that no sigma, Z-phase $(\mathrm{CrNbN})$ or $\mathrm{M}_{23} \mathrm{C}_{6}$ precipitates were observed in the aged specimens. Based on published data presence of the sigma phase in the aging regime we used is expected [3].

This study shows that $\mathrm{NbC}$ precipitates were oriented towards slip direction during creep at $850^{\circ} \mathrm{C}$ and can hinder the slip process. Study of longer creep test specimens is underway.

\section{References}

[1] T Sourmail, Materials Science and Technology, Vol 17, 1 (2001)

[2] J Källqvist, and H.-O. Andrén, Materials Science and Engineering A. 270 (1999) p.27

[3] Y Minami, H Kimura, and M Tanimura, J Materials for Energy Systems, Vol 7, 1 (1985) p.45

[4] The authors acknowledge financial support from NRCan program on Energy R\&D (PERD) 


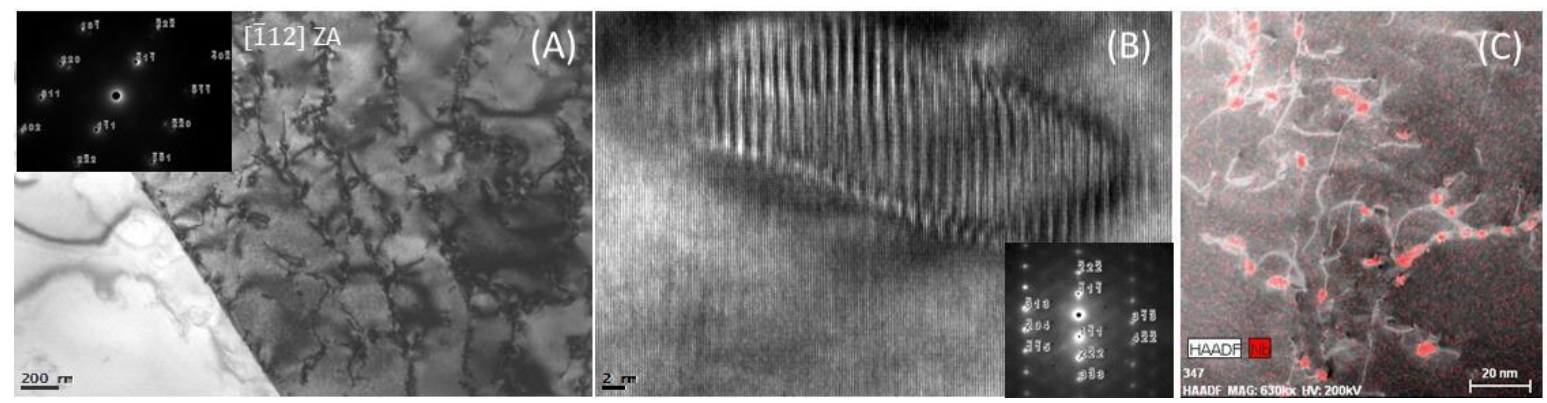

Figure 1. Micrographs showing NbC precipitates within the matrix of as received 347H: (A) TEM BF (B) HRTEM and SAD inset, (C) Overlay of Nb EDX elemental map on HAADF micrograph
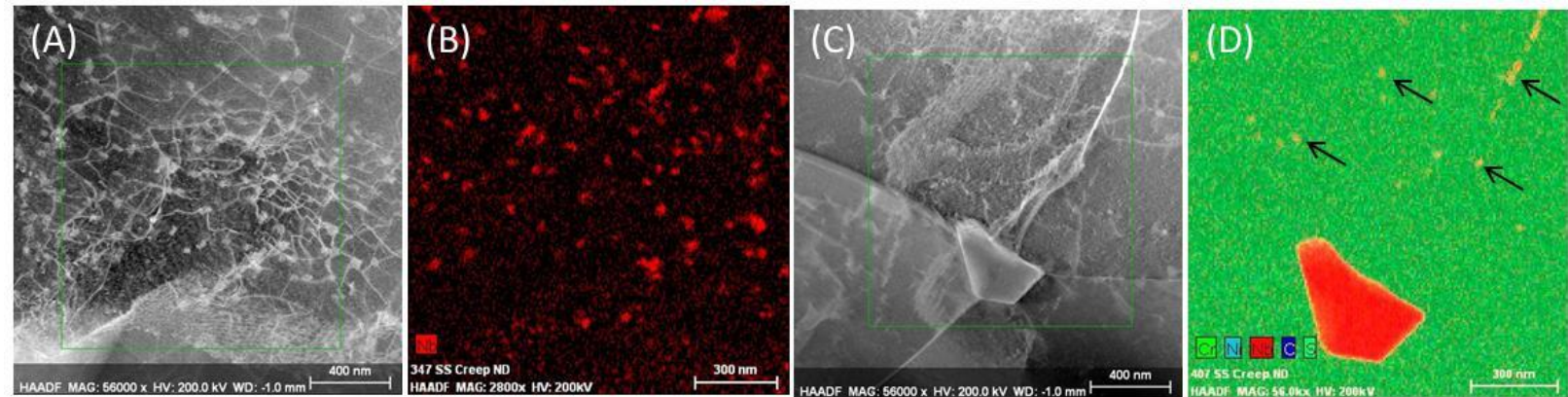

Figure 2. Distribution of $\mathrm{Nb}$ carbide precipitates within the matrix and at grain boundaries in the aged sample: (A) HAADF, (B) EDX map of $\mathrm{Nb}$, (C) HAADF of a triple joint (D) EDX map
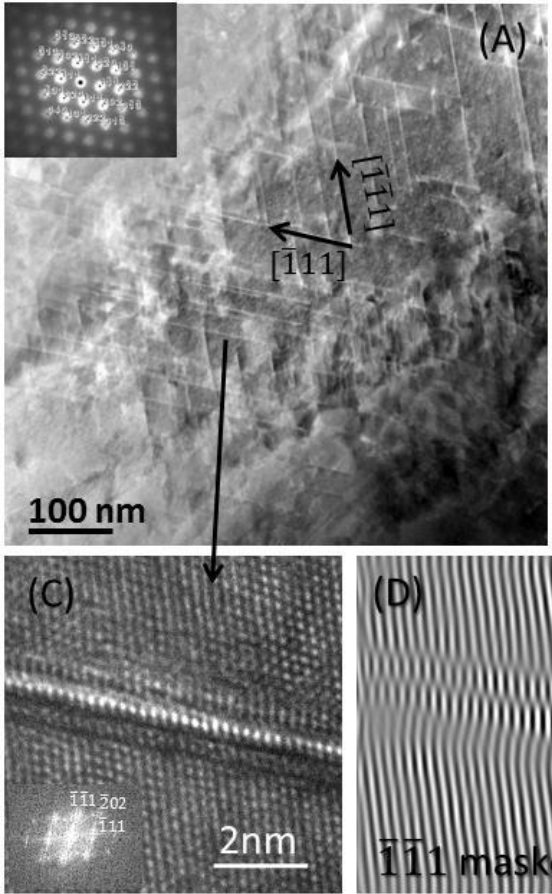
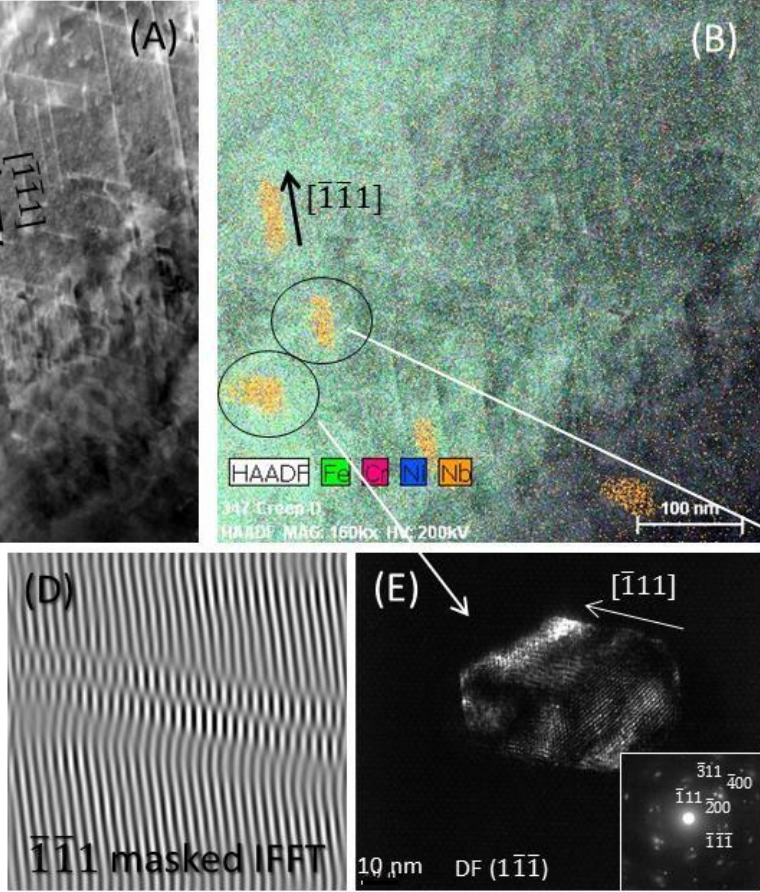
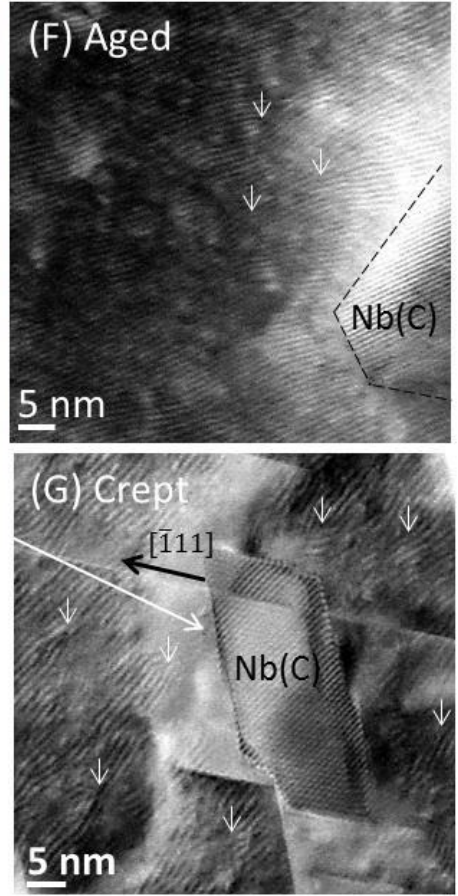

Figure 3. (A) HAADF image and CBED inset showing [ $\left.\begin{array}{lll}0 & 1 & 1\end{array}\right]$ zone axis (B) EDX map highlighting $\mathrm{NbC}$ precipitates oriented toward $<111>$, (C) HRTEM image of a slip line and FFT inset, (D) masked IFFT formed using ( $\overline{1} \overline{1} 1)$ FFT spot, (E) dark field TEM image formed using $(1 \overline{1} \overline{1})$ reflection of cubic $\mathrm{NbC}$, $(\mathrm{F})$ and $(\mathrm{G})$ high resolution STEM images from the aged (no strain) and the crept samples, respectively, with Moiré fringes highlighting the effect of deformation. 